J. Asiat. Soc. Bangladesh, Sci. 47(2): 161-171, December 2021 DOI: https://doi.org/10.3329/jasbs.v47i2.57279

\title{
PRODUCTION OF MICROALGAL BIOMASS AT DIFFERENT GROWTH PHASES TO USE AS BIOFUEL FEEDSTOCK
}

\author{
N.J. TARIN ${ }^{1}$, N.M. ALI ${ }^{2}$, A.S. CHAMON ${ }^{3}$, M.N. MONDOL ${ }^{3}$, \\ M.M. RAHMAN ${ }^{3}$ AND A. AZIZ \\ ${ }^{1}$ Institute of Water and Flood Management, BUET, Dhaka-1000, Bangladesh. \\ ${ }^{2}$ Bangladesh Tea Research Institute, Srimangal-3210, Moulvibazar, Bangladesh. \\ ${ }^{3}$ Department of Soil, Water and Environment, University of Dhaka, \\ Dhaka-1000, Bangladesh. \\ ${ }^{4}$ Department of Botany, University of Dhaka, Dhaka-1000, Bangladesh
}

\begin{abstract}
The growth of microalgae under optimized conditions was determined for assessing their growth rate and biomass production. In this study, the growth of both green algae (Chlamydomonas noctigama and Chlorella vulgaris) and cyanobacteria (Anabaena variabilis and Nostoc spongiaeforme) was measured as optical density. Chlamydomonas noctigama and Chlorella vulgaris showed the doubling time of 9.5 and 8.0 hours, respectively, whereas Anabaena variabilis and Nostoc spongiaeforme showed the doubling time of 14.8 and 16.6 hours, respectively. All the species exhibited the highest growth in terms of biomass at the phase in between stationary and death phases.
\end{abstract}

Keywords: Green algae, Cyanobacteria, Biofuel feedstock, Growth phase

\section{Introduction}

Concerns about the shortage of fossil fuels, increasing crude oil price, energy security, environment deterioration, and accelerated global warming have led to growing worldwide interests in renewable energy sources such as biofuels (Griffiths and Harrison 2009, Hanjalic et al. 2008). Bioethanol is a non-conventional fuel produced by the process of saccharification and fermentation from the bio-renewable sources, including sugars, starches, and ligno-cellulosic materials from solid wastes and plant biomass, including algal biomass, whereas biodiesel (monoalkyl esters) is one of such alternative fuel, obtained by the transesterification of triglyceride oil with monohydric alcohols (Pothiraj et al. 2015, Jasim and Maysam 2014, Blinova et al. 2015, Dvoretsky et al. 2015, Al-lwayzy et al. 2014, Christi 2007). Algal biomass, considered one of the most promising third generation biofuel feedstocks, was reported earlier by many investigators (Kumar et al. 2013, Agwa et al. 2012, Nigam and Singh 2011, Li et al. 2008).

*Corresponding author: E-mail: <chamonafrose@du.ac.bd> 
Microalgae, having massive, diversified characteristics, are emerging to be one of the most promising long-term, sustainable sources of biomass and fuel, food, feed, and other co-products (Strop 2014, Agwa et al. 2012, Milledge 2011). However, the potential for these natural resources as biofuel feedstock and other probable uses are assessed to some extent in relation to the techno-economic aspect (Quinn and Davis 2015). A few thousand algal species are reported to occur in Bangladesh's fresh water and marine environment in (Ahmed et al. 2008). Jones and Mayfield (2012) and Spolaore et al. (2006) reported a minimal commercial-scale cellulosic ethanol production because of the higher cost of production (almost twice than that ethanol production from corn). In view of the aforementioned issues, microalgae are gaining wide attention as an alternative renewable source of biomass for the production of bioethanol and biodiesel, which is grouped under 'third-generation biofuel' (Safi et al. 2014, Nigam and Singh 2011).

Algae can efficiently use $\mathrm{CO}_{2}$ and are responsible for more than $40 \%$ of the global carbon fixation, with the majority of this productivity coming from marine microalgae. They are easy to grow and cultivate anywhere with fewer energy requirements and use very few nutrients following the appropriate culture designs and systems (Nwankwo and Agwa 2019, Sharma et al. 2011, Ugwu and Aoyagi 2012). Algal strains can produce biomass very rapidly, with some species doubling in as few as 6 hours and many exhibiting two doublings per day (Hannon et al. 2010). However, the ideal growth conditions for microalgal cultures are strain-specific and requires specific natural and supplement conditions where microalgae respond with physiological alterations to the environmental growth conditions, e.g., $\mathrm{pH}$, light, temperature, aeration, nutrients, and accessible supplements (Nwankwo and Agwa 2019, Schenk et al. 2008). Higher productivity is usually considered an attribute to focus on the biochemical composition and growth characteristics of algal strains. High level of demand for clean, safe, and low-cost biomass production from selected strains requires to analysis on algal physiological response, i.e., growth under their optimum growth conditions with the possible potentials and challenges (Quinn and Davis 2015, Kim et al. 2014, Chia et al. 2013, GonzálezFernández et al. 2012, Pienkos and Darzins 2009).

\section{Materials and Methods}

Growth curves for Chlamydomonas noctigama, Chlorella vulgaris, Anabaena variabilis and Nostoc spongiaeforme were made using growth as $\mu \mathrm{g}$ chlorophyll per $\mathrm{mL}$ (chl $a$ and chl $b$ for green algae, and chl $a$ for cyanobacteria) at respective optimum conditions to define the different phases of growth as described by Vonshak and Maske (1982). 
Various optimum conditions considered as baseline for growth at different phases are given in Table 1 (Ali et al. 2016, Tarin et al. 2016).

Table 1. Optimum growth conditions for green algae and cyanobacteria.

\begin{tabular}{|c|c|c|c|c|c|c|c|}
\hline \multicolumn{2}{|c|}{ Microalgae } & \multicolumn{6}{|c|}{ Optimum growth conditions } \\
\hline & & pH & 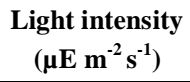 & $\begin{array}{c}\text { Temp. } \\
\left({ }^{\circ} \mathrm{C}\right)\end{array}$ & $\begin{array}{l}\text { Aeration } \\
\text { (hrs) }\end{array}$ & $\begin{array}{c}\text { Nutrient } \\
\text { element conc. }\end{array}$ & $\begin{array}{c}\text { Vitamin } \\
\text { supplement }\end{array}$ \\
\hline \multirow[t]{2}{*}{$\begin{array}{l}\text { Green } \\
\text { algae }\end{array}$} & $\begin{array}{l}\text { Chlamydomonas } \\
\text { noctigama }\end{array}$ & 6.5 & 110 & 25 & 72 & $2.0 \times$ Chu $10 \mathrm{D}$ & $\mathrm{B} 1+\mathrm{B} 6$ \\
\hline & Chlorella vulgaris & 6.5 & 110 & 25 & 72 & $1.5 \times$ Chu $10 \mathrm{D}$ & B6 \\
\hline \multirow[t]{2}{*}{$\begin{array}{l}\text { Cyano- } \\
\text { bacteria }\end{array}$} & $\begin{array}{l}\text { Anabaena } \\
\text { variabilis }\end{array}$ & 7.0 & 90 & 25 & 72 & $1.0 \times$ Chu 10D & Not required \\
\hline & $\begin{array}{l}\text { Nostoc } \\
\text { spongiaeforme }\end{array}$ & 7.5 & 70 & 25 & 72 & $1.0 \times$ Chu $10 \mathrm{D}$ & Not required \\
\hline
\end{tabular}

Growth rate and doubling time determination: Growth rate has been expressed in terms of the relative growth constant or specific growth constant ( $\mu$ ) (Fogg 1975):

$$
\mu=\log _{10} \mathrm{~N}_{\mathrm{t}}-\log _{10} \mathrm{~N}_{0} / \mathrm{t}
$$

where, $\mathrm{t}=$ Time in the hour

$$
\begin{aligned}
& \mathrm{N}_{\mathrm{t}}=\text { Biomass after } \mathrm{t} \text { hour } \\
& \mathrm{N}_{0}=\text { Biomass at " } 0 \text { " time }
\end{aligned}
$$

The maximum growth rate is defined as the maximum growth rate under light saturation at a specified temperature. The mean generation time or doubling time $(\mathrm{g})$ has been calculated from a specific growth constant, $\mu$ :

Doubling time, $g=0.0301 / \mu($ Fogg 1975)

Estimating O.D. (Optical Density): Growth was also estimated by measuring the optical density at $750 \mathrm{~nm}$ using a Shimadzu digital spectrophotometer (model UV-120-01) as described by Rodolfi et al. (2009).

Production of green algae and cyanobacteria biomass at the 3 phases of growth under optimum conditions: All the respective optimum conditions (i.e., $\mathrm{pH}$, light intensity, temperature, aeration, nutrient element concentration in medium and vitamin supplement) were provided to produce both green algae (Chlamydomonas noctigama and Chlorella vulgaris) and cyanobacteria (Anabaena variabilis and Nostoc spongiaeforme) biomass at 
their 3 phases of growth (i.e., logarithmic phase, stationary phase, and in between of stationary and death phases) where unialgal cultures were used.

Harvesting and processing of microalgal biomass: The microalgae were harvested by centrifugation at $5000 \mathrm{rpm}$ for 10 minutes using a Kokusan refrigerated centrifuge (model H-103N).

The wet algal biomass (harvested on petri dish) was dried in an oven at $60^{\circ} \mathrm{C}$ for at least 24 hours. Then the dried biomass was scrapped and stored in a plastic jar.

\section{Result and Discussion}

Estimation of growth: From the respective growth curves (Fig. 1) of microalgae used in the experiment, acceleration phase, logarithmic phase, deceleration phase, stationary phase and death phase was observed and the duration of different phases are presented in the following Table 2 .
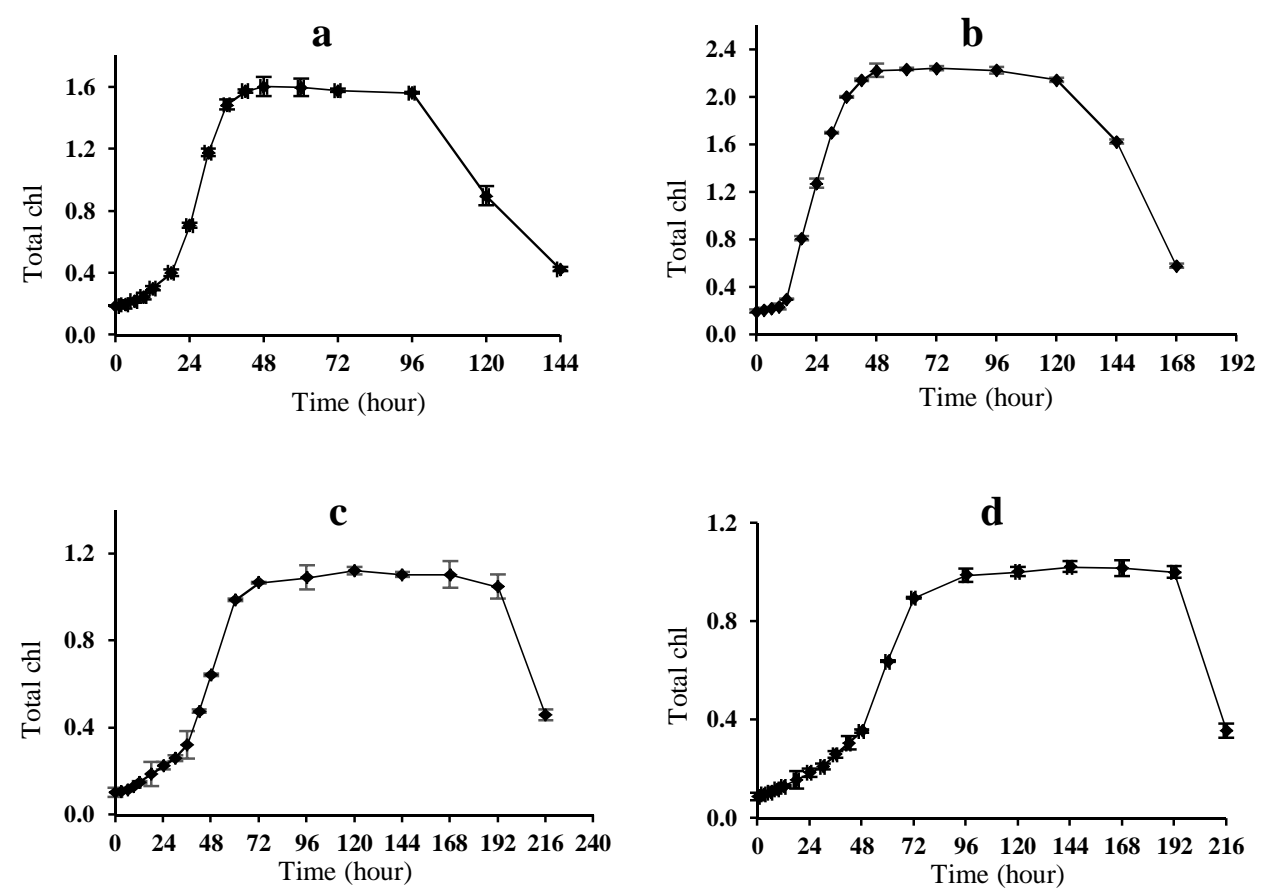

Fig. 1. Growth curve of Chlamydomonas noctigama (a), Chlorella vulgaris (b), Anabaena variabilis (c) and Nostoc spongiaeforme (d). 
There was no lag phase or initial phase in the growth curve, which may be for the reason that fresh algal strain was taken for the experiment. Cyanobacteria took more time to show the respective phase than green alga (Table 2).

Table 2. Growth phases of microalgae.

\begin{tabular}{lccccc}
\hline Microalgae & \multicolumn{5}{c}{ Growth phase with Duration (hrs) } \\
\cline { 2 - 6 } & $\begin{array}{c}\text { Acceleration } \\
\text { phase }\end{array}$ & $\begin{array}{c}\text { Logarithmic } \\
\text { phase }\end{array}$ & $\begin{array}{c}\text { Deceleration } \\
\text { phase }\end{array}$ & $\begin{array}{c}\text { Stationary } \\
\text { phase }\end{array}$ & $\begin{array}{c}\text { Death } \\
\text { phase }\end{array}$ \\
\hline $\begin{array}{l}\text { Chlamydomonas } \\
\text { noctigama }\end{array}$ & $0-18$ & $18-36$ & $36-42$ & $42-96$ & $96-$ \\
Chlorella vulgaris & $0-12$ & $12-36$ & $36-48$ & $48-120$ & $120-$ \\
Anabaena variabilis & $0-36$ & $36-60$ & $60-72$ & $72-192$ & $192-$ \\
Nostoc spongiaeforme & $0-48$ & $48-72$ & $72-96$ & $96-192$ & $192-$ \\
\hline
\end{tabular}

Before the log-growth phase, all the microalga started to be divided towards growth by $18,12,36$, and $48 \mathrm{hrs}$, respectively. Moreover, both the green alga had the logarithmic growth within $36 \mathrm{hrs}$, whereas $A$. variabilis increased by $60 \mathrm{hrs}$ and $N$. spongiaeforme showed growth exponentially by $72 \mathrm{hrs}$. Following the maximum growth phase, Chlamydomonas noctigama appeared at the deceleration phase within $42 \mathrm{hrs}$ and Chlorella vulgaris showed that within $48 \mathrm{hrs}$ where the cyanobacteria (A. variabilis and $N$. spongiaeforme) took the slowing down phase in 72 and $96 \mathrm{hrs}$, correspondingly. The periods in between stationary and death phase were found as 42-96, 48-120, 72-192 and 96-192 hrs for Chlamydomonas noctigama, Chlorella vulgaris, A. variabilis and $N$. spongiaeforme, separately after which the isolates started to be dead.

Growth rate and doubling time determination: The growth rate and doubling time of Chlamydomonas noctigama, Chlorella vulgaris, Anabaena variabilis and Nostoc spongiaeforme are given below in Table 3.

Table 3. Growth rate and doubling time of Chlamydomonas noctigama, Chlorella vulgaris, Anabaena variabilis and Nostoc spongiaeforme.

\begin{tabular}{lcc}
\hline Microalgae & Growth rate $(\boldsymbol{\mu}),\left(\mathbf{h r}^{-\mathbf{1}}\right)$ & Doubling Time $(\mathbf{g}),(\mathbf{h r s})$ \\
\hline Chlamydomonas noctigama & 0.0316 & 9.5 \\
Chlorella vulgaris & 0.0037 & 8.0 \\
Anabaena variabilis & 0.0020 & 14.8 \\
Nostoc spongiaeforme & 0.0181 & 16.6 \\
\hline
\end{tabular}


The doubling time (g) of Chlamydomonas noctigama was $9.5 \mathrm{hrs}$ which was similar to the finding of Hemaiswarya et al. (2013). Again, Chlorella vulgaris exhibited a doubling time of $8 \mathrm{hrs}$. In contrast, Maxwell et al. (1994) showed that during the exponential phase of growth Chlorella vulgaris had a doubling time of $8.6 \mathrm{hrs}$ at a temperature of $27^{\circ} \mathrm{C}$. The reason behind the less time for doubling shown by Chlorella vulgaris may be the trend of fast-growing with the optimum environmental conditions. Anabaena variabilis exhibited a doubling time of $14.8 \mathrm{hrs}$ while different strains of Anabaena showed a doubling time of 18-24 hrs observed by Prasanna et al. (2006). Meeks et al. (1983) observed that the doubling time of Anabaena 7120 and A. cylindrical in nitrogen free BG11 medium was 21.5 and $18.2 \mathrm{hrs}$, respectively. Besides, Nostoc spongiaeforme had a doubling time of $16.6 \mathrm{hrs}$ which was less than that reported by Rodriguez et al. (1986) for Nostoc sp.

Production of Chlamydomonas noctigama, Chlorella vulgaris, Anabaena variabilis, and Nostoc spongiaeforme biomass at the 3 phases of growth under optimum conditions: The biomass of microalgae (Chlamydomonas noctigama, Chlorella vulgaris, Anabaena variabilis and Nostoc spongiaeforme) (as $\mathrm{mg} / \mathrm{L}$ ) at 3 different phases of their growth under respective optimum conditions were presented in Fig. 2. The test of significance of different treatment means was computed by Duncan's New Multiple Range Test (DMRT) at a 5\% level. The result was statistically significant at the 5\% level.

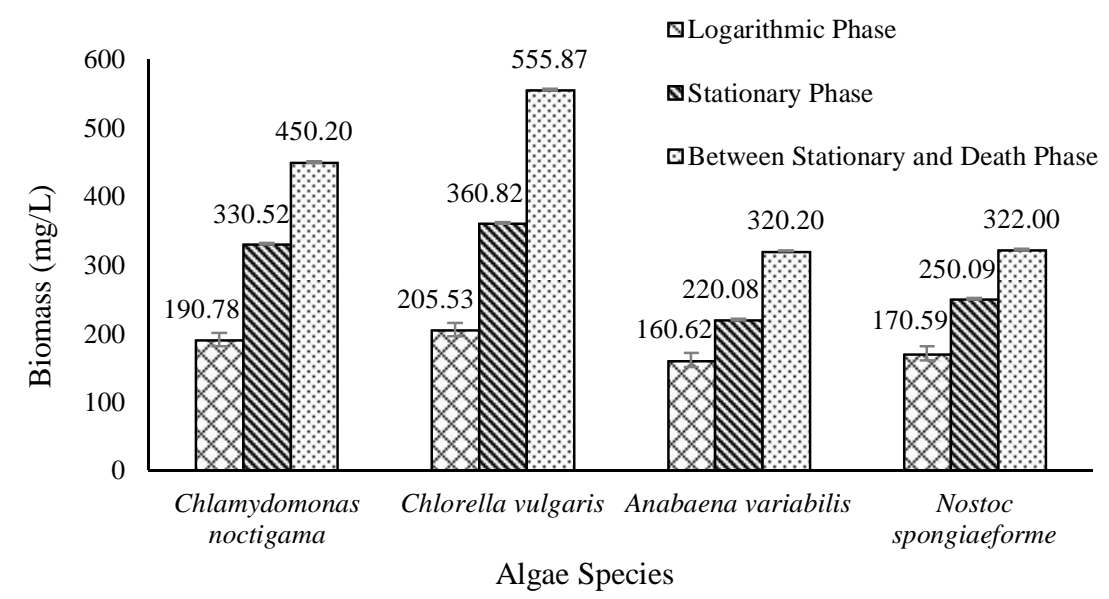

Fig. 2. Microalgal biomass (as $\mathrm{mg} / \mathrm{L}$ ) at 3 different growth phases under respective optimum conditions.

The result showed significant differences in the amount of biomass (as $\mathrm{mg} / \mathrm{L}$ ) obtained from the algal species (Chlamydomonas noctigama, Chlorella vulgaris, Anabaena 
variabilis and Nostoc spongiaeforme) at 3 different phases of growth under the respective optimum conditions.

About Chlamydomonas noctigama, the highest biomass $(450.20 \mathrm{mg} / \mathrm{L})$ at the phase between stationary and death phase and the lowest biomass $(190.78 \mathrm{mg} / \mathrm{L})$ at the logarithmic phase under the optimum conditions were found statistically different and also from the biomass at the stationary phase $(330.52 \mathrm{mg} / \mathrm{L})$ under the optimum conditions.

In the case of Chlorella vulgaris, the highest biomass $(555.87 \mathrm{mg} / \mathrm{L})$ at the phase between stationary and death phase and the lowest biomass $(205.53 \mathrm{mg} / \mathrm{L})$ at the logarithmic phase under the optimum conditions were found statistically different from each other and also from the biomass obtained at the stationary phase $(360.82 \mathrm{mg} / \mathrm{L})$ under the optimum conditions.

Regarding Anabaena variabilis, the highest biomass $(320.20 \mathrm{mg} / \mathrm{L})$ at the phase between stationary and death phase and the lowest biomass $(160.62 \mathrm{mg} / \mathrm{L})$ at the logarithmic phase under the optimum conditions were found statistically different from each other and also from the biomass obtained at the stationary phase $(220.08 \mathrm{mg} / \mathrm{L})$ under the optimum conditions.

In the case of Nostoc spongiaeforme, the highest biomass $(322.00 \mathrm{mg} / \mathrm{L})$ at the phase between stationary and death phase and the lowest biomass $(170.59 \mathrm{mg} / \mathrm{L})$ at the logarithmic phase under the optimum conditions were found statistically different and also from the biomass at the stationary phase $(250.09 \mathrm{mg} / \mathrm{L})$ under the optimum conditions.

Both the green alga (Chlamydomonas noctigama and Chlorella vulgaris) and cyanobacteria (Anabaena variabilis and Nostoc spongiaeforme) showed the highest growth in terms of biomass at the phase between stationary and death phase. This phase of growth may provide the final concentration of biomass. It might be because the biomass parameter remains constant during this phase, according to Vonshak and Maske (1982). The depletion of some essential nutrients in the medium becomes limited inhibiting the growth and results into the death, in this regard.

Among all the microalgae (both green algae and cyanobacteria) in this experiment, green alga Chlorella vulgaris had the highest growth in terms of biomass $(555.87 \mathrm{mg} / \mathrm{L})$ at the phase between stationary and death phase under the optimum growth conditions considered. This result showed the similarity to the study by Yatirajula et al. (2019), where the growth phase was observed after the stationary phase though the duration was 
varied due to the respective optimum conditions. It can be recommended to use biofuel feedstock for the biofuel, e.g. bioethanol and biodiesel, instead of conventional energy source (fossil fuel, coal, petroleum, natural gas, etc.) that are usually known as nonrenewable sources of energy. The acceptability of the green alga, Chlorella vulgaris, as a potential biofuel feedstock is found worldwide, as mentioned by Ru et al. (2020), Varaprasad et al. (2020), Purkan et al. (2019), Ramírez-López et al. (2019), Sakarika and Kornaros (2019), Papapolymerou et al. (2018), Suthar and Verma (2018), Daliry et al., (2017), Lam et al. (2017), Rajanren and Ismail (2016), Villagracia et al. (2016), El-Sayed et al. (2015), Safi et al. (2014), Jasim and Maysam (2014), Mallick et al. (2011), Phukan et al. (2011), though the amount of biomass produced can vary due to the production scale, operational design, and optimum growth conditions taken under consideration.

\section{Conclusion}

All the randomly isolated and selected freshwater microalgae produced variable amounts of biomass with variable growth rates at different phases of their life cycles. The algal strains can be used as a source of biomass for biofuel and other valuable products if growing at the phase between stationary and death phase under the set of optimum conditions. Further research for analysis and large-scale biomass production by considering the highest amount with the growth phase is required.

\section{Acknowledgments}

The authors gratefully acknowledge the financial support from the Centre for Advanced Studies and Research in Biological Sciences, University of Dhaka for carrying out the research and the Department of Botany, University of Dhaka for providing laboratory facilities, particularly for giving access in the growth room.

\section{References}

Agwa, O.K., S.N. Ibe and G.O. Abu. 2012. Biomass and lipid production of freshwater algae Chlorella sp. using locally formulated media. Int. Res. J. Microbiol. 3: 285-288.

Ahmed, Z.U., Z.N.T. Begum, M.A. Hassan, M. Khondker, S.M.H. Kabir, M. Ahmed, A.T.A. Ahmed, A.K.A. Rahman and E.U. Haque (eds.). 2008. Encyclopedia of Flora and Fauna of Bangladesh. Vol.3. Algae, Chlorophyta. Asiat. Soc. Bangladesh, Dhaka. pp. 591-592.

Ali, N.M., N.J. Tarin, M.N. Mondol, A.S. Chamon, A. Aziz and M.M. Rahman. 2016. Optimization of growth of two microalgal isolates for biofuel feedstock. Bangladesh J. Sci. Ind. Res. 51(3): 183-192. 
Al-lwayzy, S.H., T. Yusaf and R.A. Al-Juboori. 2014. Biofuels from the fresh water microalgae Chlorella vulgaris (FWM-CV) for diesel engines. Energies. 7(3): 1829-1851.

Blinova, A., A. Bartosova and K. Gerulova. 2015. Cultivation of microalgea (Chlorella vulgaris) for biodiesel production. Research papers, Faculty of Materials Science and Technology in Irnava Slovak University of Technology in Bratislava. 23(36): 87-95.

Chia, M.A., A.T. Lombardi and M.G.G. Melão. 2013. Growth and biochemical composition of Chlorella vulgaris in different growth media. An. Acad. Bras. Ciênc. (Annals of the Brazilian Academy of Sciences). 85(4): 1427-1438.

Christi, Y. 2007. Biodiesel from microalgae. Biotechnol. Advan. 25: 294-306.

Daliry, S., A. Hallajisani, J. Mohammadi Roshandeh, H. Nouri and A. Golzary. 2017. Investigation of optimal condition for Chlorella vulgaris microalgae growth. Global J. Environ. Sci. Manage. 3(2): 217-230.

Dvoretsky, D., S. Dvoretsky, E. Peshkova and M. Temnov. 2015. Optimization of the process of cultivation of microalgae Chlorella vulgaris biomass with high lipid content for biofuel production. Chem. Eng. Trans. 43: 361-366

El-Sayed, A.B., M.G. Mahamoud and S.R. Hamed. 2015. Complementary production of biofuels by the green alga Chlorella vulgaris. Int. J. Renew, Energ. Res. 5(3, 2): 943-963.

Fogg, G.E. 1975. Algal Cultures and Phytoplankton Ecology. $2^{\text {nd }}$ Ed., University of Wisconsin Press, Madison. pp. 175.

González-Fernández, C., B. Sialve, N. Bernet and J.P. Steyer. 2012. Impact of microalgae characteristics on their conversion to biofuel. Part II: Focus on biomethane production. Biofuels Bioprod. Biorefin. 6(2): 205-218.

Griffiths, M.J. and S.T.L. Harrison. 2009. Lipid productivity as a key characteristic for choosing algal species for biodiesel production. J. Appl. Phycol. 21: 493-507.

Hemaiswarya, S., R. Raja, R. Ravikumar, A.Y. Kumar and I.S. Carvalho. 2013. Microalgal Omics and Their Applications. In: Barh, D., V. Zambare and V. Azevedo (eds.). OMICS: Applications in Biomedical, Agricultural and Environmental Sciences. CRC Press. pp. 439450.

Hanjalic, K., Van de Krol and R. Lekic. 2008. Sustainable Energy Technologies: Options and Prospects. Springer, New York. pp. 227-249.

Hannon, M., J. Gimpell, M. Tran, B. Rasala1 and S. Mayfield. 2010. Biofuels from algae: challenges and potential. Biofuels 1(5): 763-784.

Jasim, M.S. and A.M. Maysam. 2014. Bioethanol production from green algae Chlorella vulgaris under different concentration of nitrogen. Asian J. Natur. Appl. Sci. 3: 27-36.

Jones, C.S. and S.P. Mayfield. 2012. Algae Biofuels: Versatility for the Future of Bioenergy. Curr. Opin. Biotechnol. 23(3): 346-351.

Kim, D.G., C. Lee, S.M. Park and Y.E. Choi. 2014. Manipulation of light wavelength at appropriate growth stage to enhance biomass productivity and fatty acid methyl ester yield using Chlorella vulgaris. Bioresour. Technol. 159: 240-248.

Kumar, S., R. Gupta, G. Kumar, D. Sahoo and R.C. Kuhad. 2013. Bioethanol Production from Gracilaria verrucose, A Red Alga in A Biorefinary Aproach. Bioresour. Technol. 135: 150-156.

Lam, M.K., M.L. Yusoff, Y. Uemura, J.W. Lim, C.G. Khoo, K.T. Lee and H.C. Ong. 2017. Cultivation of Chlorella vulgaris using nutrients source from domestic wastewater for biodiesel production: Growth condition and kinetic studies. Renew. Energy 103: 197-207. 
Li, Y., M. Horsman, N. Wu, C.Q. Lan and N. Dubois-Calero. 2008. Biofuels from microalgae. Biotechnol. Progr. 24: 815-820.

Mallick, N., S. Mandal, A.K. Singh, M. Bishai and A. Dash. 2011. Green microalga Chlorella vulgaris as a potential feedstock for biodiesel. J. Chem. Technol. Biotechnol. 87(1): 137-145.

Maxwell, D.P., S. Falk, C.G. Trick and N.P.A. Huner. 1994. Growth at Low Temperature Mimics High-Light Acclimation in Chlorella vulgaris. Plant Physiol. 105: 535-543.

Meeks, J.C., K.L. Wycoff, J.S. Chapman and C.S. Enderlin. 1983. Regulation of Expression of Nitrate and Dinitrogen Assimilation by Anabaena species. Appl. Environ. Microbiol. 54: 1351-1359.

Milledge, J.J. 2011. Commercial application of microalgae other than as biofuels: a brief review. Rev. Environ. Sci. Biotechnol. 10: 31-41.

Nigam, P.S. and A. Singh. 2011. Production of Liquid Biofuels from Renewable Resources. Prog. Ener. Combust. Sci. 37(1): 52-68.

Nwankwo, U.N. and O.K. Agwa. 2019. Growth Response of Chlorella vulgaris to Cultivation on Different Cassava Waste Mixtures. Electronic J. Biol. 15(3): 68-78.

Papapolymerou, G., V. Karayannis and N. Gougoulias. 2018. Growing Chlorella vulgaris into bioreactors set in solar greenhouse, towards biofuel: Nutrient composition. J. Appl. Biotechnol. Bioeng. 5(2): 106-110.

Phukan, M.M., R.S. Chutia, B.K. Konwar and R. Kataki. 2011. Microalgae Chlorella as a potential bio-energy feedstock. Appl. Energy 88: 3307-3312.

Pienkos, P.T. and A. Darzins. 2009. The promise and challenges of microalgal-derived biofuels. Biofuels Bioprod. Biorefin. 3: 431-440.

Pothiraj, C., A. Arun and M. Eyini. 2015. Simultaneous saccharification and fermentation of cassava waste for ethanol production. Biofuel. Res. J. 2: 196-202.

Prasanna, R., R. Kumar, A. Sood, B.M. Prasanna and P.K. Singh. 2006. Morphological, Physiological and Molecular Characterization of Anabaena Strains. Microbiologic. Res. 161: 187-202.

Purkan, P., E. Nidianti, A. Abdulloh, A. Safa, W. Retnowati, W. Soemarjati, H. Nurlaila and S.W. Kim. 2019. Biodiesel Production by Lipids from Indonesian strain of Microalgae Chlorella vulgaris. Open Chem. 17: 919-926.

Quinn, J.C. and R. Davis. 2015. The potentials and challenges of algae based biofuels: a review of the techno-economic, life cycle, and resource assessment modeling. Bioresour. Technol. 184: 444-452.

Rajanren, J.R. and H.M. Ismail. 2016. Investigation of Chlorella vulgaris microalgae as a source for renewable fuel. Biofuels. 8(1): 37-47.

Ramirez-Lopez, C., H.V. Perales-Vela and L. Fernandez-Linares. 2019. Biomass and lipid production from Chlorella vulgaris UTEX 26 cultivated in $2 \mathrm{~m}^{3}$ raceway ponds under semicontinuous mode during the spring season. Bioresour. Technol. 274: 252-260.

Rodolfi, L., G.C. Zittelli, N. Bassi, G. Padovani, N. Biondi, G. Bonini and M.R. Tredici. 2009. Microalgae for Oil: Strain Selection, Induction of Lipid Synthesis and Outdoor Mass Cultivation in a Low-Cost Photobioreactor. 102(1): 100-112.

Rodriguez, H., J. Rivas, M.G. Guerrero and G. Losada. 1986. Selection of nitrogen-fixing bluegreen algae for biomass photoproduction. In: Proceedings of the 1986 International Congress on Renewable Energy. Vol.1. Consejo Superior De Investigaciones Cientificas, Madrid, Spain. pp. 183-186. 
Ru, I.T.K., Y.Y. Sung, M. Jusoh, M.E.A. Wahid and T. Nagappan. 2020. Chlorella vulgaris: a perspective on its potential for combining high biomass with high value bioproducts. Appl. Phycol. 1(1): 2-11.

Safi, C., B. Zebib, O. Merah, P. Pontalier and C. Vaca-Garcia. 2014. Morphology, composition, production, processing and applications of Chlorella vulgaris: A review. Renew. Sustain. Ener. Rev. Elsevier. 35: 265-278.

Sakarika, M. and M. Kornaros. 2019. Chlorella vulgaris as a green biofuel factory: comparison between biodiesel, biogas and combustible biomass production. Bioresour. Technol. 273: 237243.

Schenk, P., S. Thomas-Hall, E. Stephens, U. Marx, J. Mussgnug, C. Posten, O. Kruse and B. Hankamer. 2008. Second Generation Biofuels: High-Effiency Microalgae for Biodiesel Production. Bioenergy Res. 1: 20-43.

Sharma, R., G.P. Singh and V.K. Sharma. 2011. Comparison of different media formulations on growth, morphology and chlorophyll content of green algae Chlorella vulgaris. Int. J. Pharm. Biologic. Sci. 2(2): 509-516.

Spolaore, P., C. Joannis-Cassan, E. Duran and A. Isambert. 2006. Commercial applications of microalgae. J. Biosci. Bioeng. 101(2): 87-96.

Strop, P. 2014. Versatility of microbial transglutaminase. Rinat-Pfizer Inc., 230 East Grand Avenue, South Francisco, California 94080, United States. Bioconjugate Chem. 25(5): 855862.

Suthar, S. and R. Verma. 2018. Production of Chlorella vulgaris under varying nutrient and abiotic conditions: a potential microalga for bioenergy feedstock. Process. Saf. Environ. Prot. 113: 141-148.

Tarin, N.J., N.M. Ali, A.S. Chamon, M.N. Mondol, M.M. Rahman and A. Aziz. 2016. Optimizing Chlorella vulgaris and Anabaena variabilis Growth Conditions for Use as Biofuel Feedstock. J. Asiat. Soc. Bangladesh, Sci. 42(2): 191-200.

Ugwu, C.U. and H. Aoyagi. 2012. Microalgal culture systems: an insight into their designs, operation and applications. Biotech. 11(3): 127-132.

Varaprasad D., N. Ragasudha, K. Paramesh, P. Chandramati Shankar, S. Nazaneen Parveen and T. Chandrasekhar. 2020. Production of Bioethanol from Green Alga Chlorella Vulgaris: An Important Approach to Utilize Algal Feedstock or Waste. In: Ghosh S., R. Sen, H. Chanakya and A. Pariatamby (eds.). Bioresource Utilization and Bioprocess. Springer, Singapore. pp. 57-65.

Villagracia, A.R.C., A.P. Mayol, A.T. Ubando, J.B.M.M. Biona, N.B. Arboleda, M.Y. David, R.B. Tumlos, H. Lee, O.H. Lin and R.A. Espiritu. 2016. Microwave drying characteristics of microalgae (Chlorella vulgaris) for biofuel production. Clean. Technol. Environ. Policy. 18: 2441-2451.

Vonshak, A. and H. Maske. 1982. Algae: Growth Techniques and Biomass Production. In: Coombs, J. and D.O. Hall (eds.). Techniques in Bioproductivity and Photosynthesis. Pergamon Press, Oxford, New York. pp. 66-77.

Yatirajula, S.K., A. Shrivastava, V.K. Saxena and J. Kodavaty. 2019. Flow behavior analysis of Chlorella vulgaris microalgal biomass. Heliyon. Elsevier. 5: 1-7.

(Revised copy received on 15.11.2021) 